OAK RIDGE

NATIONAL LABORATORY

MANAGED BY UT-BATTELLE

FOR THE DEPARTMENT OF ENERGY
ORNLTM-2000/153

\section{Support Facility for a Graphite Target Neutrino Factory}

\author{
Philip T. Spampinato \\ Joel B. Chesser \\ Tony A. Gabriel \\ Franz X. Gallmeier \\ John R. Haines \\ Richard A. Lillie \\ Thomas J. McManamy
}


ORNL/TM-2000/153

\title{
Support Facility for a Graphite Target Neutrino Factory
}

\author{
Philip T. Spampinato, Joel B. Chesser, Tony A. Gabriel, Franz X. Gallmeier,
} John R. Haines, Richard A. Lillie, and Thomas J. McManamy

Date Published-August 2000

Prepared by the OAK RIDGE NATIONAL LABORATORY

Oak Ridge, Tennessee 37831

managed by

UT-Battelle, LLC

for the

U.S. DEPARTMENT OF ENERGY

under contract DE-AC05-00OR22725 


\section{s}




\section{TABLE OF CONTENTS}

PREFACE

ACKNOWLEDGMENTS ........................................................................

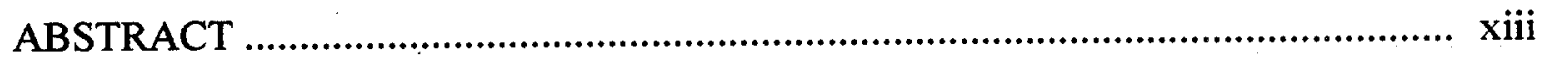

1. TARGET SUPPORT FACILITY ……...................................................... 1

1.1. DESIGN REQUIREMENTS AND ASSUMPTIONS …………................... 2

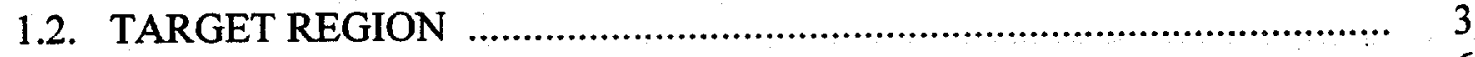

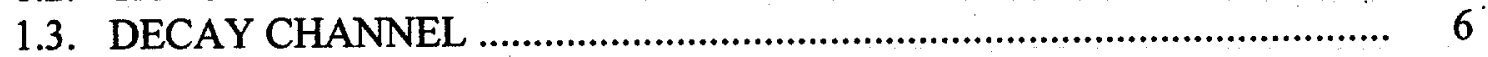

2. GRAPHITE TARGET …........................................................................ 9

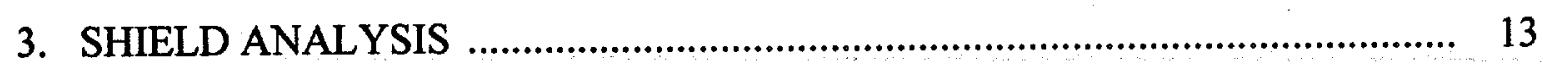

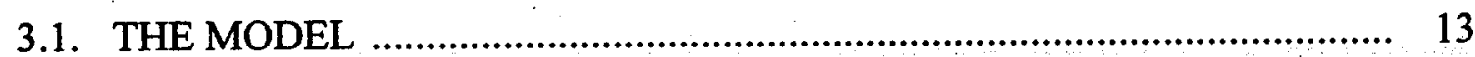

3.2. RESULTS .............................................................................. 14

3.3. SHIELD DESIGN .............................................................................. 14

3.4. BEAM ABSORBER FLUX CONTRIBUTION ........................................ 17

4. CRANE HALL AND REMOTE HANDLING ................................................. 19

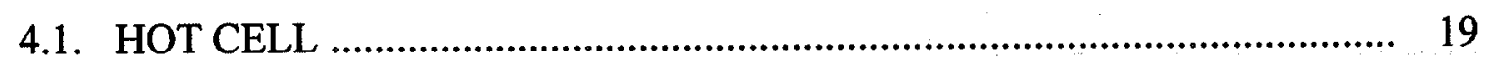

4.2. REMOTE-HANDLING EQUIPMENT …............................................... 19

4.3. REMOTE-HANDLING OPERATIONS …........................................... 20

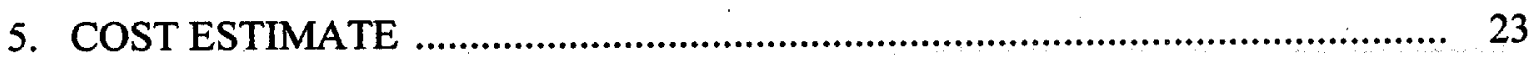

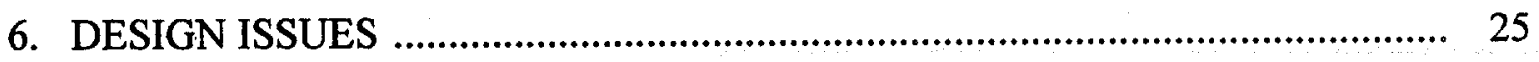

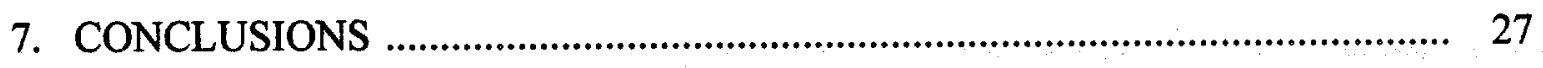

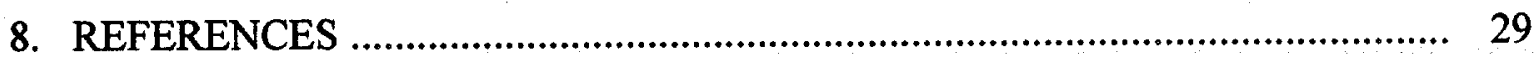





\section{LIST OF FIGURES}

Figure

1 Overview of the Target Support Facility

2 Side elevation of the Target Support Facility

3 Cutaway view of the high-field solenoid, target, and shielding in the cryostat module

4 Arrangement of the graphic target and support tube

5 Relative angular arrangement of the PB and muon decay channel

6 Section cut through the target support tube

7 Section cut through the target showing the arrangement of the magnets and the shield

8 Typical cross section of the decay channel

9 Peak graphite target temperature

10 Saturation pressure and erosion rate for graphite as a function of temperature

11 Surface sublimation rate for a graphite target as a function of power deposition

12 Neutron spectra in vacuum zones of the high-field magnet and the low-field tunnel

13 Gamma spectra in vacuum zones of the high-field magnet and the low-field tunnel

14 Proton spectra in vacuum zones of the high-field magnet and the low-field tunnel

15 Side elevation of the hot-cell area

16 Section cut through the hot cell 
" 


\section{LIST OF TABLES}

1 Component lifetimes for the Target Support Facility .............................. 2

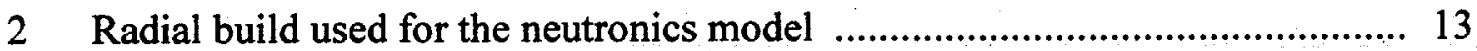

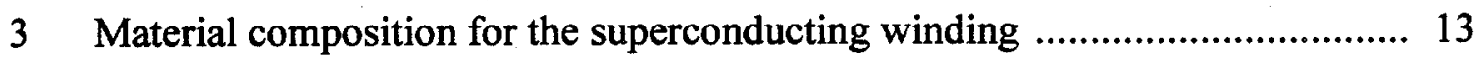

4 Radial build of the decay channel components ...................................... 14

5 Dose levels in the target region and the decay channel region, in $\mathrm{mrem} / \mathrm{h}$ at $1.5-\mathrm{MW}$ beam power ............................................................ 15

6 Shield thickness estimate in the first 15 meters of the decay channel ............ 17

7 Total neutron and gamma fluxes without the beam absorber contribution downstream to $Z=16 \mathrm{~m}$

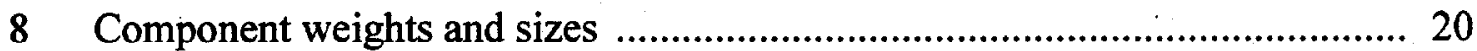

9 Summary of the Target Support Facility costs ..................................... 23

10 Detailed listing of the Target Support Facility construction costs ................. 24

11 Detailed listing of the Target Support Facility equipment costs .................... 25 
,

*

. 


\section{PREFACE}

This report summarizes the conceptual design work developed at Oak Ridge National Laboratory for the Target Support Facility of a neutrino producing research facility. The Target Support Facility is one of the many systems that make up the overall design of a Neutrino Factory concept developed by Fermi National Accelerator Laboratory (FNAL). The unique features of the facility are the radiatively-cooled graphite target and the numerous superconducting solenoid magnets. FNAL developed this work as a participant in the Muon Collider/ Neutrino Factory Collaboration.

The basis for much of the design of the Target Support Facility is a result of the MARS code, a high energy physics simulation that establishes hadron yields, magnetic requirements, and shielding estimates. The code simulations were done at FNAL.

The Target Support Facility consists of the target region where pions and muons are produced, the crane hall which covers the length of the muon decay channel, the hot cell where radioactive components are handled, and radiation-handling equipment such as manipulators and remotely operated tools. The support facility comprises a structure that is $10-\mathrm{m}$ wide by $80-\mathrm{m}$ in length.

The report presents details of the various elements of the facility, the design concept of the graphite target, radiation shield analysis, remote handling aspects of the facility, and a preliminary cost estimate. 


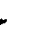

. 


\section{ACKNOWLEDGMENTS}

This work was performed at Oak Ridge National Laboratory, managed by UT-Battelle, LLC, for the U.S. Department of Energy under contract DE-AC05-00OR22725.

The authors express their appreciation to Drs. Sam Childress, Nikolai Mokhov, and Norbert Holtkamp of the Fermi National Accelerator Laboratory for insight and guidance in developing the engineering details of the Target Support Facility. And a special acknowledgment is directed to K. S. Harber whose hard work and attention to detail made publishing this report possible. And finally, the authors thank R. W. Sharpe for his valuable editorial comments. 
. 


\begin{abstract}
The Target Support Facility for a Neutrino Producing Research Facility extends from the pretarget, primary beam focusing region to the end of the decay channel. Technical components include the target, beam absorber, and solenoid magnetic-field focusing system. While the ultimate goal is to target about $4 \mathrm{MW}$ of proton beam in the target area, smaller values and different target materials (e.g., low Z) are considered to facilitate the first step. As detailed in this report, a carbon target was chosen with an incident primary beam power of $1.5 \mathrm{MW}$. The target is embedded in a high-field solenoid magnet of $20 \mathrm{~T}$, followed by a transition section channel, where the field tapers down to 1.25 T. An iterative design process has been carried out which optimizes Monte Carlo code flux projections with realistic magnetic-field parameters. The severe radiation environment and component shielding requirements strongly influence design choices.

The overall system design includes the capture and decay channel solenoids, the design parameters of which were provided by the National High Magnetic Field Laboratory. This design balances resistive and superconducting magnet contributions. Facility requirements, including shielding, remote handling, radioactive water system, etc. are based on the final design goal of $4 \mathrm{MW}$. The extent of the Target Support Facility and radiation-handling equipment includes the $50-\mathrm{m}$ decay channel, where remote-handling operations are also required.
\end{abstract}




\section{TARGET SUPPORT FACILITY}

The Target Support Facility for the neutrino production research facility consists of the target region, crane hall, hot cell, and radiation-handling equipment. It comprises a structure that is about $10 \mathrm{~m}$ wide by $80 \mathrm{~m}$ in length and is positioned partially over the proton beam (PB) window region, the target region, and the entire length of the decay channel. The 16-GeV PB-target interaction produces significant levels of neutrons and neutron-induced gamma activation: therefore, the facility requires significant shielding, provisions for remote-handling equipment, and a hot cell. The radiation-handling equipment, which is used to replace the target and remotely handle life-limited components, is arranged to have a minimal impact on the facility design. A linear crane hall provides lift coverage to the areas over the target region, the decay channel, and the hot cell. There is ample "laydown" space for storing shield blocks, which are removed to gain access to components in the target region and the decay channel. A 40-ton bridge crane and a bridge-mounted manipulator operate along the full length of the crane hall. Figure 1 is a cutaway view of the overall facility, including the first $16 \mathrm{~m}$ of the decay channel. It is noted that some of the design approaches implemented in theTarget Support Facility are the result of work done for the Spallation Neutron Source, in the areas of facility design and remote-handling considerations [1].

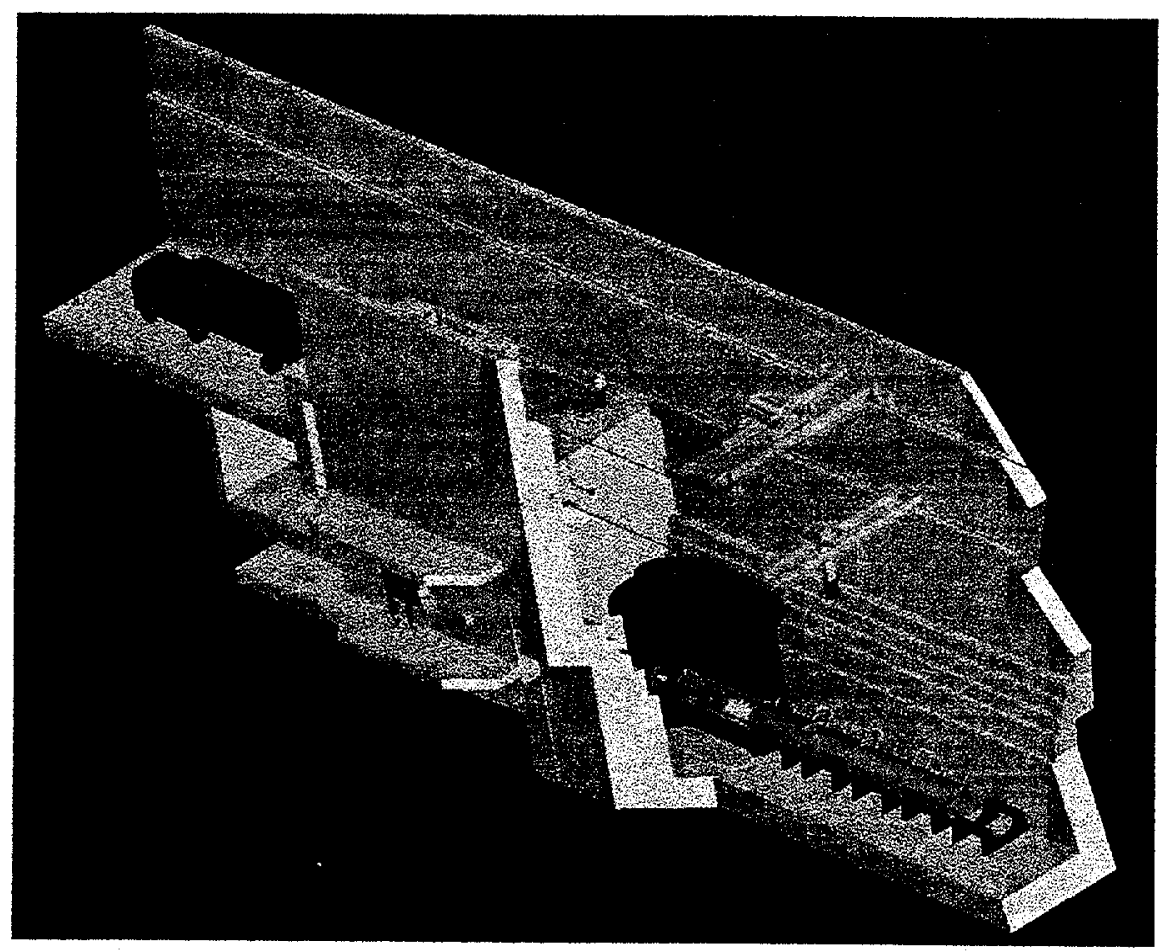

Fig. 1. Overview of the Target Support Facility.

Figure 2 is a side elevation, which shows the arrangement of the target region, the upstream end of the decay channel, the hot cell over the downstream end of the PB tunnel, and the crane hall over the entire facility. 


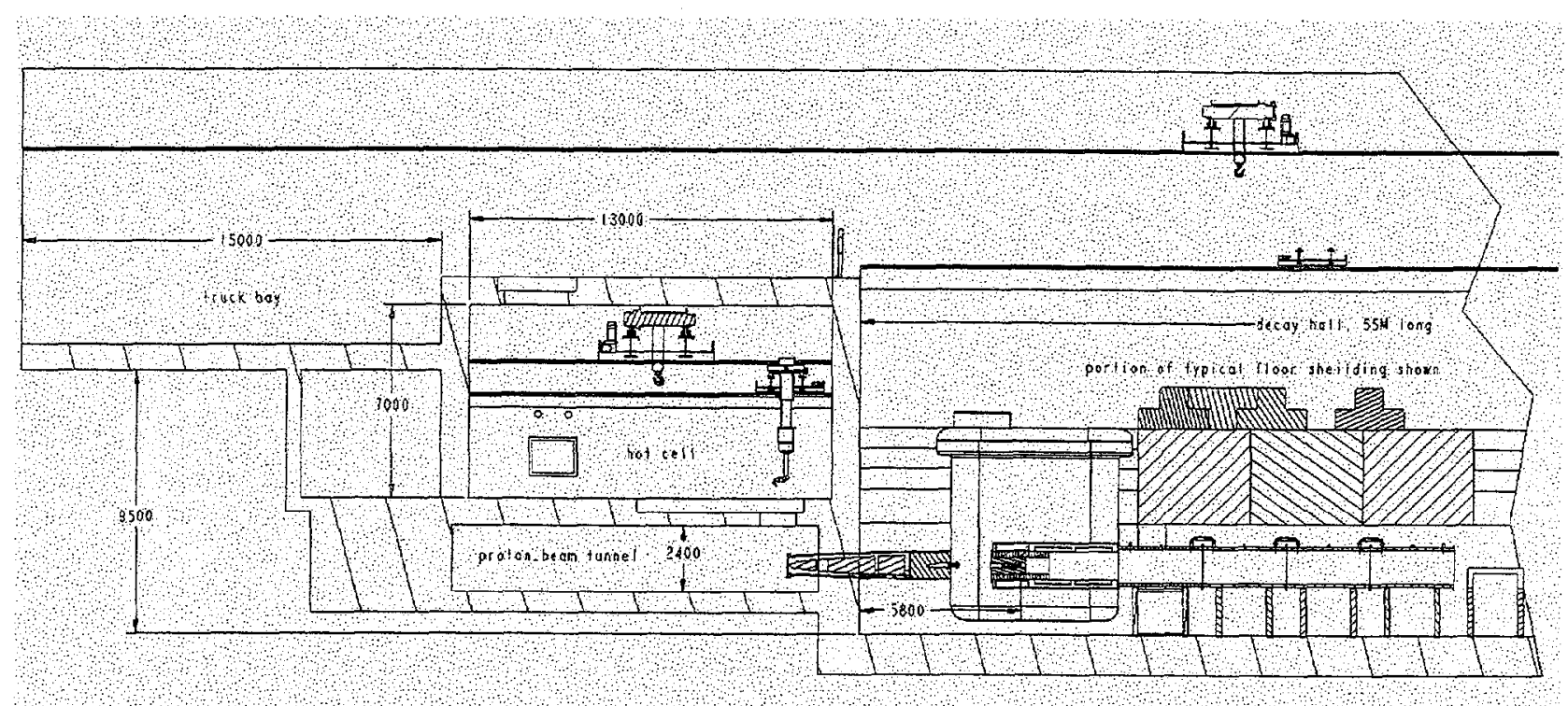

Fig. 2. Side elevation of the Target Support Facility.

\subsection{DESIGN REQUIREMENTS AND ASSUMPTIONS}

The shielding for the neutrino production facility is designed for a $16-\mathrm{GeV}, 4-\mathrm{MW}$ $\mathrm{PB}$, although initial operations will be at $1.5 \mathrm{MW}$. The Neutrino Source Facility has an operating availability of $2 \times 10^{7}(\sim 232$ days/year) for all systems; therefore, annual downtime for scheduled and unscheduled maintenance activities, including those of the Target System, is $133 \mathrm{~d} /$ calendar year (CY) [2,3].

The major components in the Target Support Facility are expected to survive for the life of the facility, that is, $>20$ years; in addition there are life-limited components, which require periodic replacement. Table 1 lists these component lifetimes based on radiation-damage criteria and a preliminary allocation of downtime for their replacement. The life-limited components greatly influenced the design of the Target Support Facility.

Table 1. Component lifetimes for the Target Support Facility

\begin{tabular}{|l|c|c|}
\hline \multicolumn{1}{|c|}{ Component } & Expected lifetime & Replacement time \\
\hline Target & 3 months & 6 days \\
\hline Target + Bitter coil & 6 months & 7 days \\
\hline Target +Bitter coil + PB window & 1 year & 8 days \\
\hline PB instrumentation & 1 year & $5-7$ days \\
\hline Beam dump & 5 years & 1.5 months \\
\hline High Field S/C coils & $>20$ years & $9-12$ months \\
\hline Low Field S/C coils & $>20$ years & $9-12$ months \\
\hline
\end{tabular}




\subsection{TARGET REGION}

The target region is the focus of remote-handling activities, which are carried out every three months. The region consists of a helium-atmosphere vessel, which contains steel shielding, a passively cooled graphite target module, a high-field solenoid magnet assembly, and the PB window. The vessel (shown in Fig. 1) is approximately $4 \times 6 \times 7 \mathrm{~m}$ with a removable lid. The smaller $2-\mathrm{m}$ diam port on the lid is removed for routine replacement of the components listed in Table 1. The large lid can be removed if a superconducting coil in the first cryostat module ever needs replacing. The magnet assembly consists of a demountable resistive solenoid (Bitter coil), which is replaced every 6 months; a lifetime tungsten-steel shield; and a lifetime superconducting solenoid. These components are contained in a helium atmosphere, which prevents air-activation when the PB is on and minimizes evaporation of the graphite target. Figure 3 shows the target and magnet components.

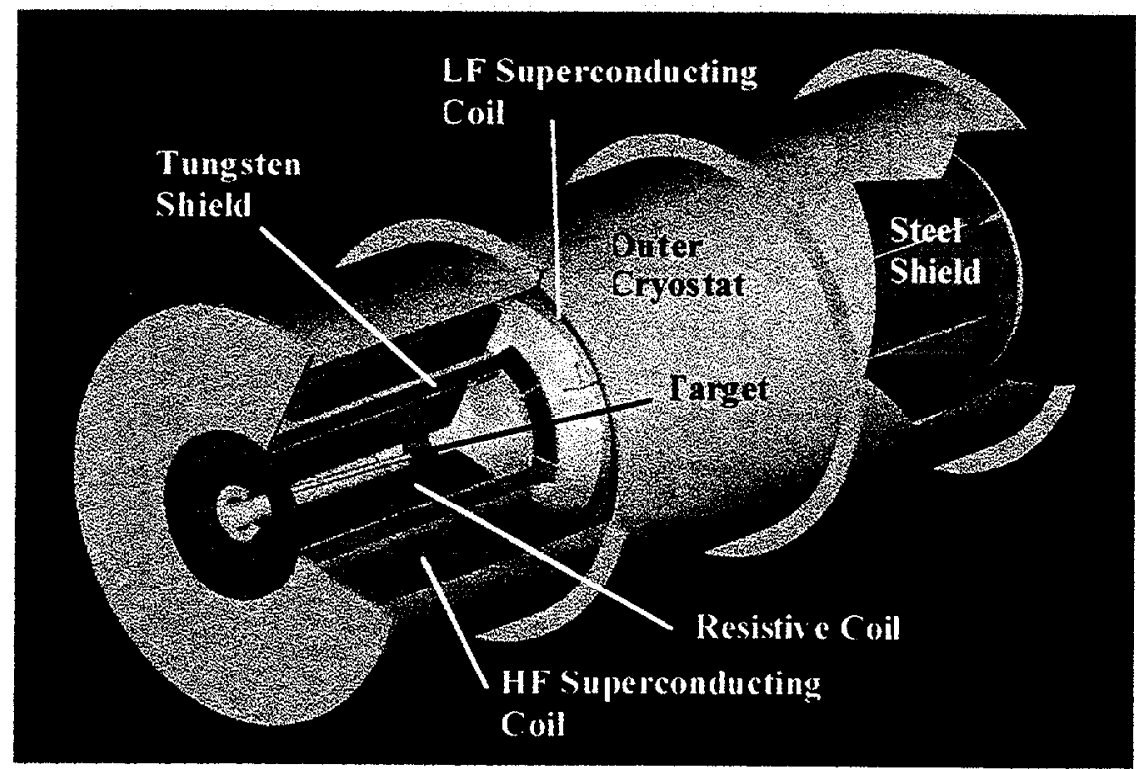

Fig. 3. Cutaway view of the high-field solenoid, target, and shielding in the cryostat module.

The target is a graphite rod $1.5 \mathrm{~cm}$ in diameter by $80 \mathrm{~cm}$ long. The target is held in place by two spoke-like graphite supports, in a 15-cm-diam stainless steel (SS) support tube. The target is radiatively cooled to the water-cooled surface of the support tube. Figure 4 shows the graphite target rod supported by graphite spokes, which are mounted to a SS support tube. The axis of the target is parallel to the PB line, but the axis is oriented at 50 milliradians relative to the axis of the support tube. The support tube is aligned with the magnetic axis of the solenoid coils and is mounted into the bore of the Bitter coil. Therefore, the overall axis of the target support facility has a 50 milliradian offset relative to the PB tunnel in the horizontal plane, as is shown in Fig. 5. Figure 6 depicts a section cut through the support tube near the downstream spokes. (Note that Fig. 3 is a cutaway view of the target module mounted in the solenoid coil structure.) 
Figure 7 reveals a section through the cryostat that shows the arrangement of the high-field magnets, the target, and the radiation shield.

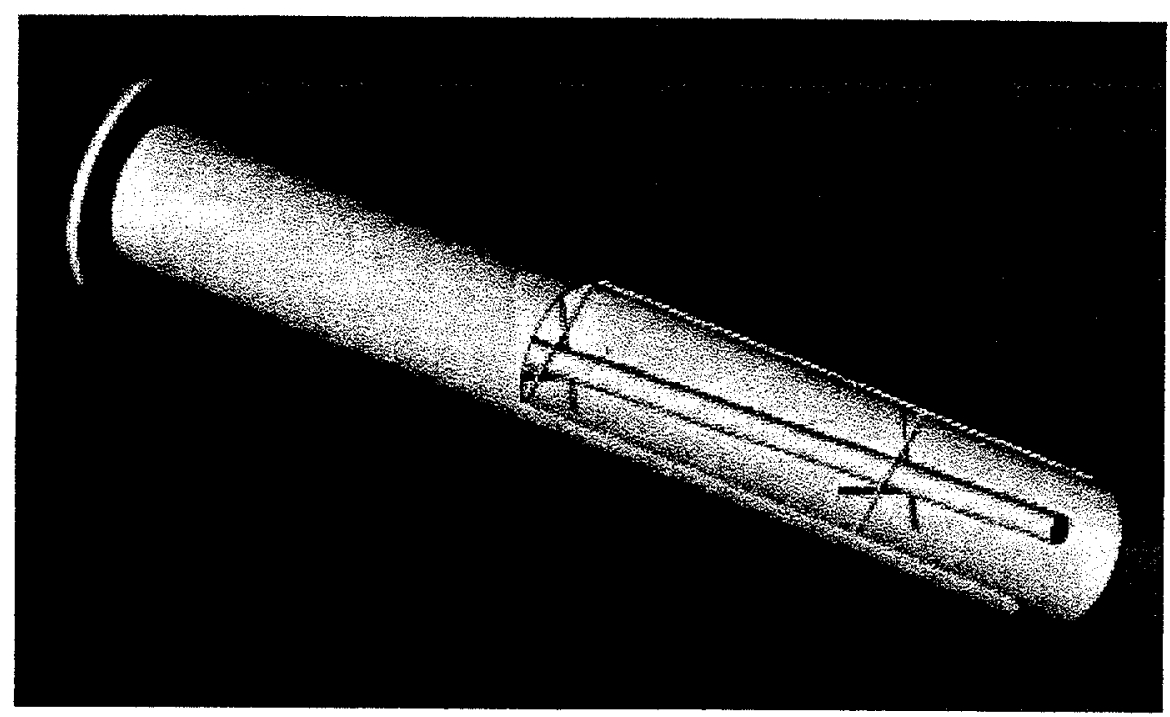

Fig. 4. Arrangement of the graphic target and support tube.

Preliminary analysis of the target indicates that radiative cooling and low thermal stresses are achievable. For a uniform heating distribution throughout the target, internal thermal stresses were determined to be $1 / 5$ the strength of graphite. Therefore, it appears that radiation damage may limit the target lifetime. A damage criterion of 5 displacements per atom (dpa) was chosen to be a reasonable limit; this equates to approximately 3 calendar months before the target must be replaced. (Sublimation of the target is not an issue since it operates at a temperature of about $1850^{\circ} \mathrm{C}$ and is in a helium environment.) Additional analysis is required to better understand an important remaining issue-shock wave effects from the 3-ns-duration beam spill.

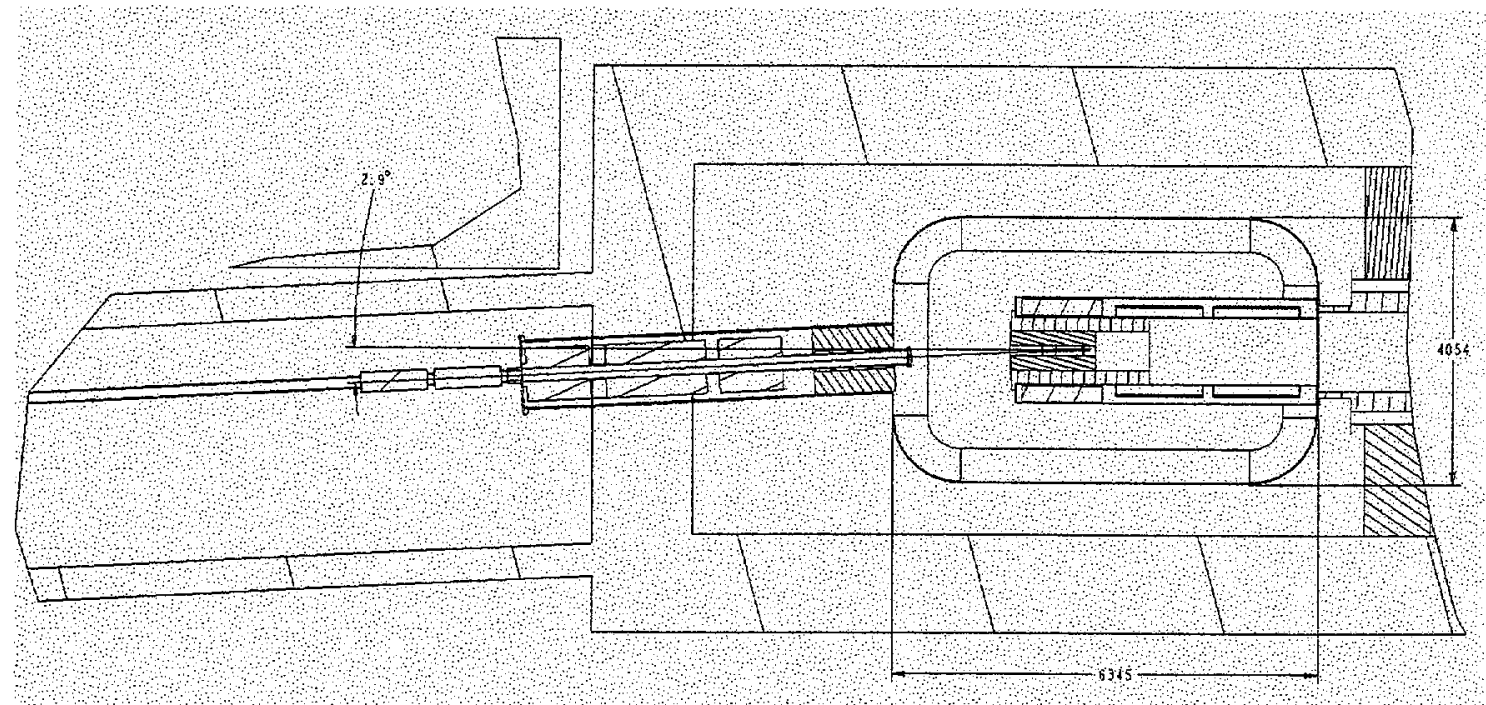

Fig. 5. Relative angular arrangement of the PB and muon decay channel. 


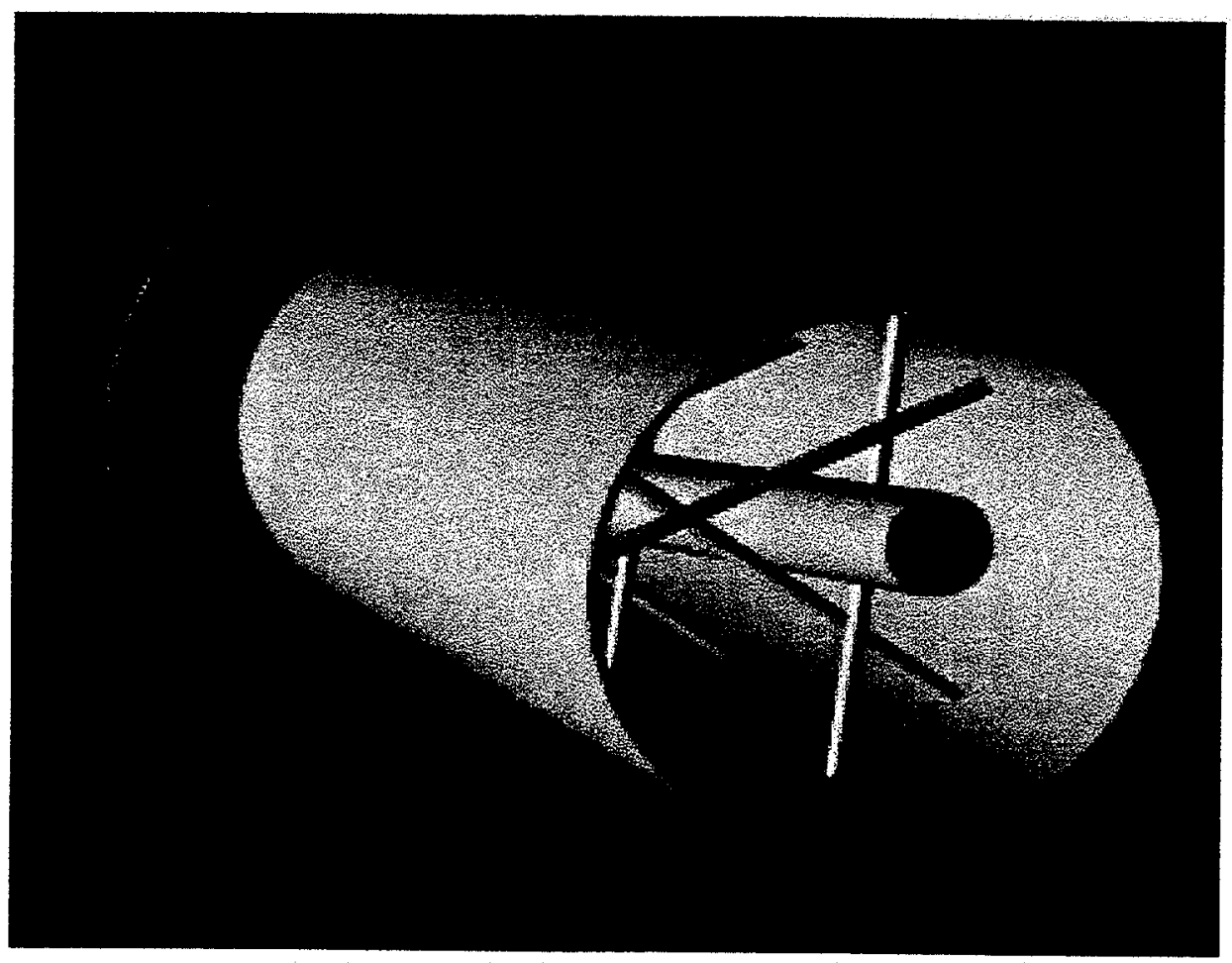

Fig. 6. Section cut through the target support tube.

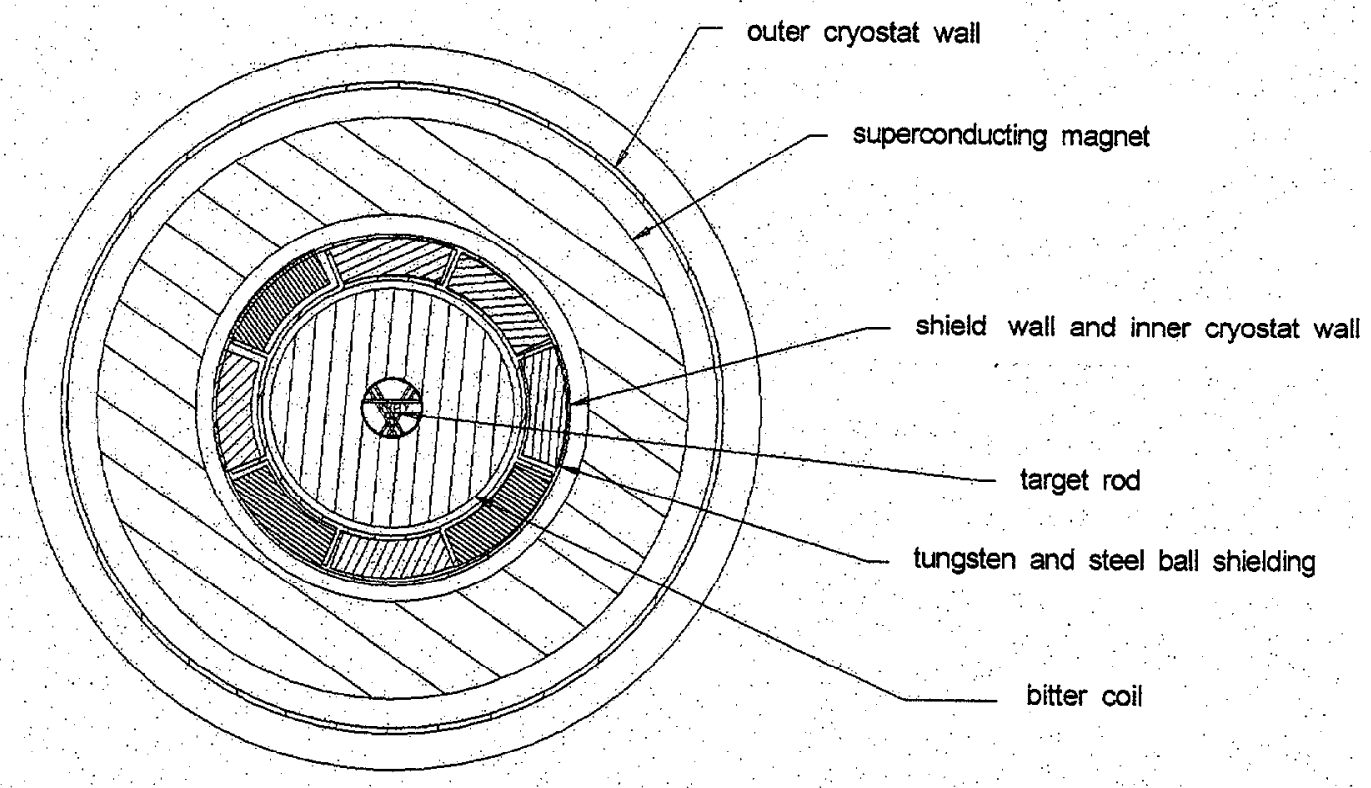

Fig. 7. Section cut through the target showing the arrangement of the magnets and the shield. 
The Bitter solenoid is mounted within the bore of a tungsten radiation shield, as shown in Figs. 3 and 7. The shield limits neutron heating to the high-field superconducting coil (HFSC); protects the coil from radiation damage; and, because of its high density, minimizes the diameter of this costly superconducting magnet. The shield is a SS structure, which is water-cooled and filled with tungsten-carbide balls under the HFSC, but the structure contains steel balls under the other three coils. The HFSC and the first three low-field coils are assembled in a common cryostat, which is located within the helium vessel. A common cryostat was used so that the coil-to-coil axial magnetic forces could be reacted within the cryostat, thereby avoiding external structure with its inherent thermal leaks to the coils.

The target is surrounded by steel shield blocks, which limit the prompt radiation effects to the surrounding area. Two meters of steel are required on the sides and bottom of the target module to meet the requirement for ground-water protection, and about $4.5 \mathrm{~m}$ of steel and $0.5 \mathrm{~m}$ of concrete are needed above the target to limit the dose rate at the crane hall floor to $0.25 \mathrm{mrem} / \mathrm{h}$.

\subsection{DECAY CHANNEL}

The 50-m-long decay channel is a tunnel-like structure, which is below the crane hall and which is located under about $5 \mathrm{~m}$ of removable shield slabs. Figure 8 shows a cross section of the decay channel. The shield slabs are removable to gain access to the 12 cryostat modules, each of which contains 4 low-field superconducting coils (LFSC). Under normal operations the decay channel does not require access since the LFSC are lifetime components. Each of the cryostat modules are mechanically joined together so that the inner cryostat surface makes up the vacuum boundary of the muon decay channel, but the outer cryostat surface is in an air atmosphere. The LFSC cryostat modules are similar to that shown in Fig. 3.

The low-field solenoids are protected from nuclear heating and radiation damage by a 30-cm-thick, water-cooled SS shield. The first low-field cryostat in the decay channel also contains a beam dump, which is located at $5.5<\mathrm{Z}<6.5 \mathrm{~m}$ to absorb the portion of PB that passes through the target. In this beam dump region, the LFSC may require a diameter larger than the adjacent LFSC coils to accommodate the thickness of the beamabsorber module, coolant lines, and a suitable nuclear shield thickness. Downstream of the beam dump at the end of the first low-field cryostat, a 60-cm-diam. titanium window is in place to separate the helium atmosphere from the vacuum in the remainder of the decay channel. The shield requirements in the decay channel are virtually the same as those in the vicinity of the target because of the large diameter of the muon channel. Access into the decay channel requires lifting shield slabs weighing up to 40 tons and then storing the slabs in the crane hall. 


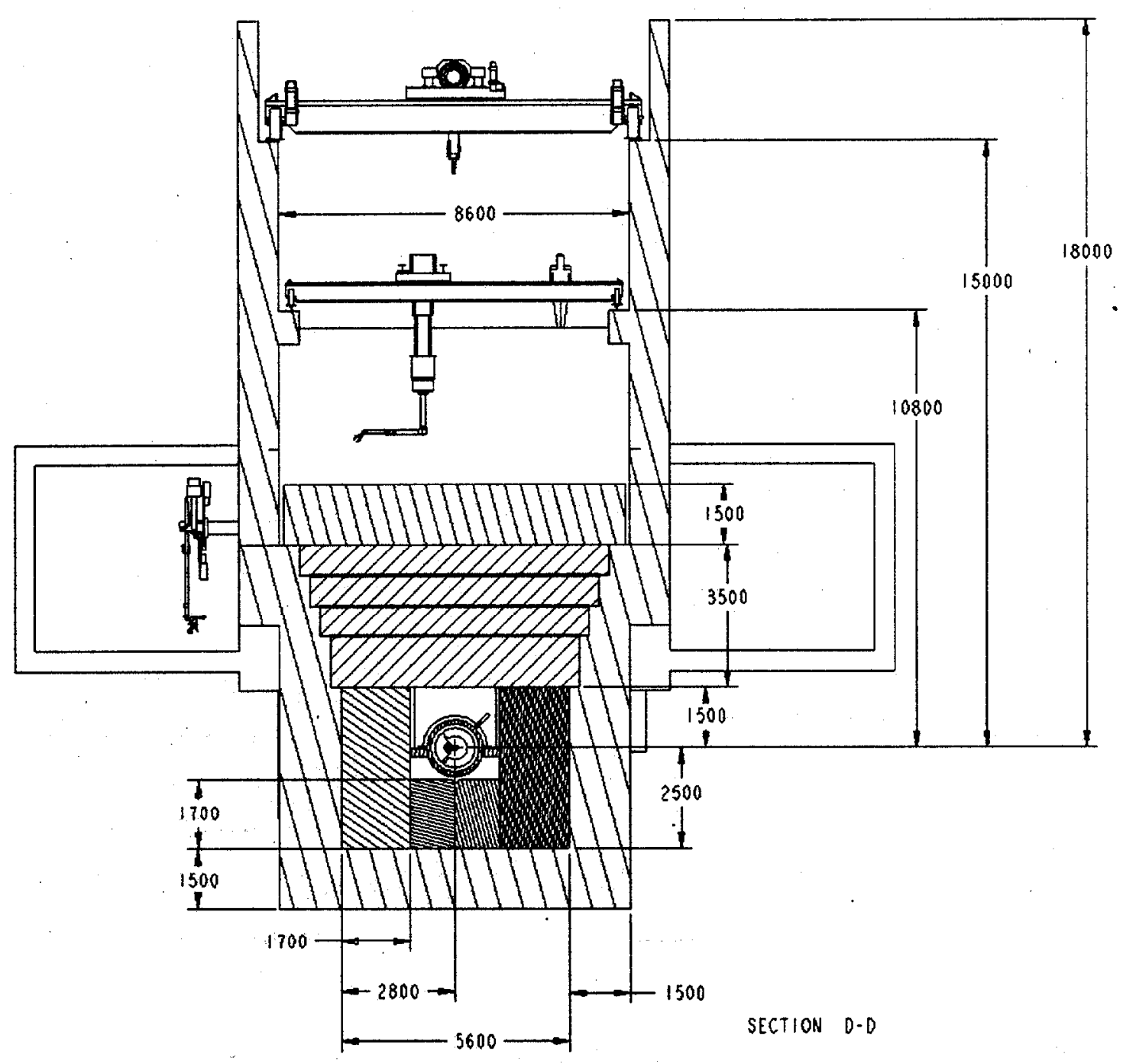

Fig. 8. Typical cross section of the decay channel. 



\section{GRAPHITE TARGET}

Preliminary thermal and structural analyses of a radiatively-cooled graphite target for the neutrino production research facility were performed to address feasibility of the concept and identify key issues that need to be considered in further R\&D efforts.

Based on Mokhov's results [2], the time-averaged power deposition in the $15-\mathrm{mm}$ diameter and $800-\mathrm{mm}$ long target is $35 \mathrm{~kW}$. Assuming for these initial studies that this power is deposited uniformly along the axial length of the target, the volumetric power deposition in the target is about $250 \mathrm{MW} / \mathrm{m}^{3}$. The target surface temperature required to radiate the deposited power to a water-cooled tube is estimated to be about $1850^{\circ} \mathrm{C}$. The temperature at the center of the target is about $75^{\circ} \mathrm{C}$ hotter.

Thermal stresses caused by the nonlinear temperature distribution from the center of the graphite to its surface were estimated assuming that the target is free to expand axially. For the nominal case, i.e., uniform heating distribution the peak tensile stress is about $5 \mathrm{MPa}$ compared to a typical tensile strength for graphite of about $30 \mathrm{MPa}$ or larger.

The sensitivity of the graphite surface temperature to the volumetric power deposition is shown in Fig. 9. If the peak power deposition in the graphite is twice that of the average (uniform distribution) value, the surface temperature becomes $2260^{\circ} \mathrm{C}$ and the peak thermal stress is about $10 \mathrm{MPa}$. These are conservative estimates, since axial conduction through the graphite will tend to reduce them.

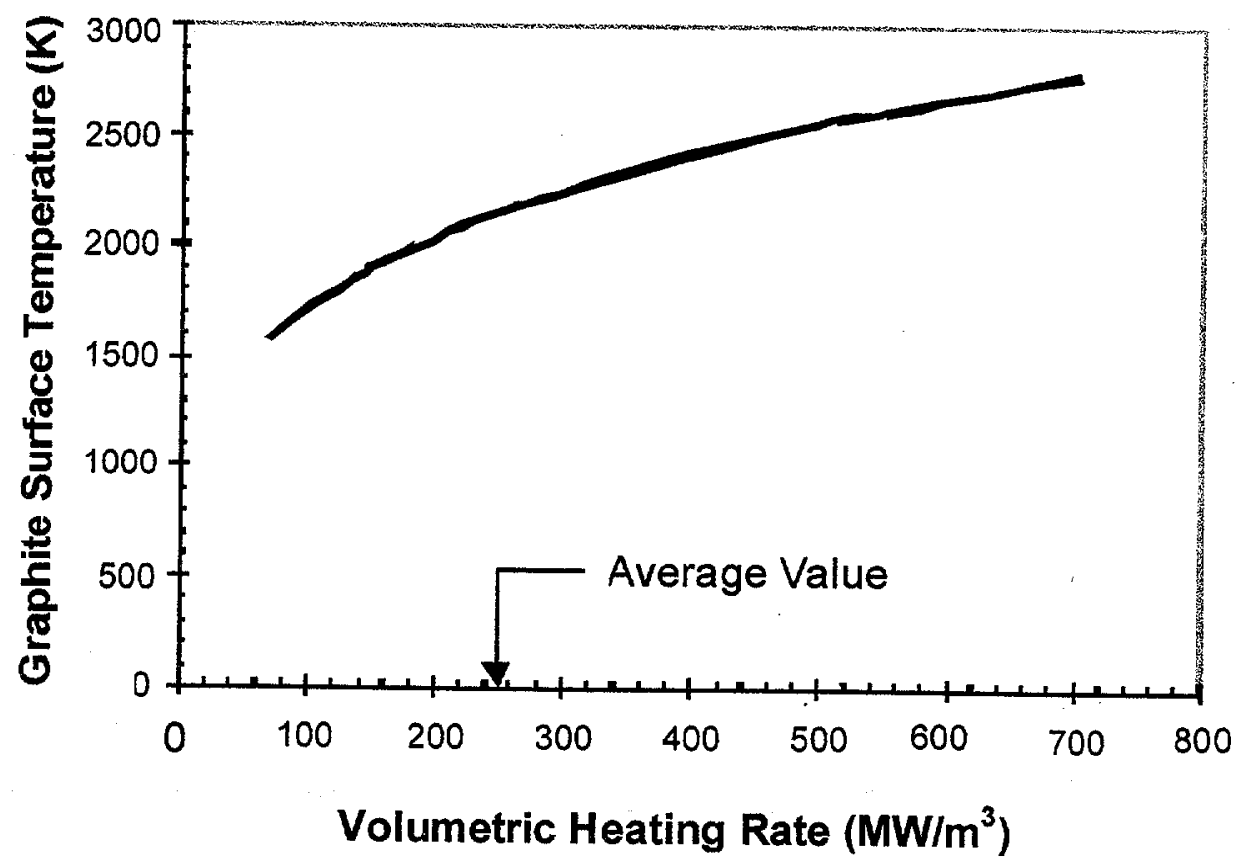

Fig. 9. Peak graphite target temperature. 
The amount of sublimation expected when operating at these elevated temperatures was estimated assuming that the graphite is submersed in a perfect vacuum environment. The actual sublimation rate should be significantly reduced in the proposed helium environment; nonetheless, this estimate serves as an upper bound on the erosion rate. Results are plotted in Fig. 10 as a function of temperature and in Fig. 11 as a function of power deposition. At the nominal, i.e., average power deposition value of $250 \mathrm{MW} / \mathrm{m}^{3}$, the surface recession rate is only $5 \mu \mathrm{m} / \mathrm{d}$; however if the actual power deposition were twice this nominal value, then the recession rate would be $5 \mathrm{~mm} / \mathrm{d}$, a rate which is clearly unacceptable.

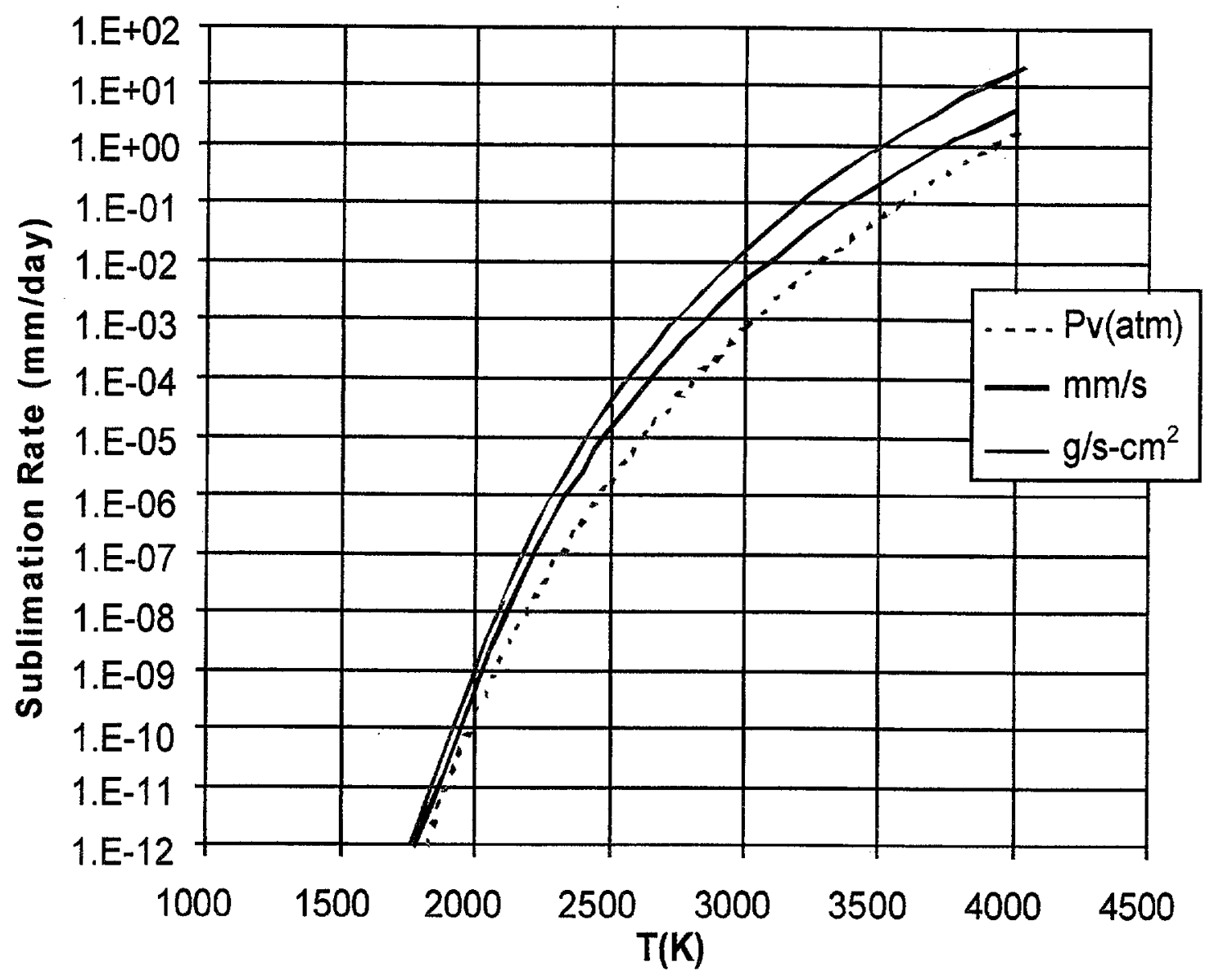

Fig. 10. Saturation pressure and erosion rate for graphite as a function of temperature.

These highly sensitive results demonstrate the need for future efforts to (1) predict the axial power deposition in the graphite target; (2) use this power deposition information to determine the temperature distribution with a realistic model including axial conduction as well as radiation heat transfer; and (3) perform tests to determine the sublimation rate for graphite in helium environments over a practical range of pressures. 


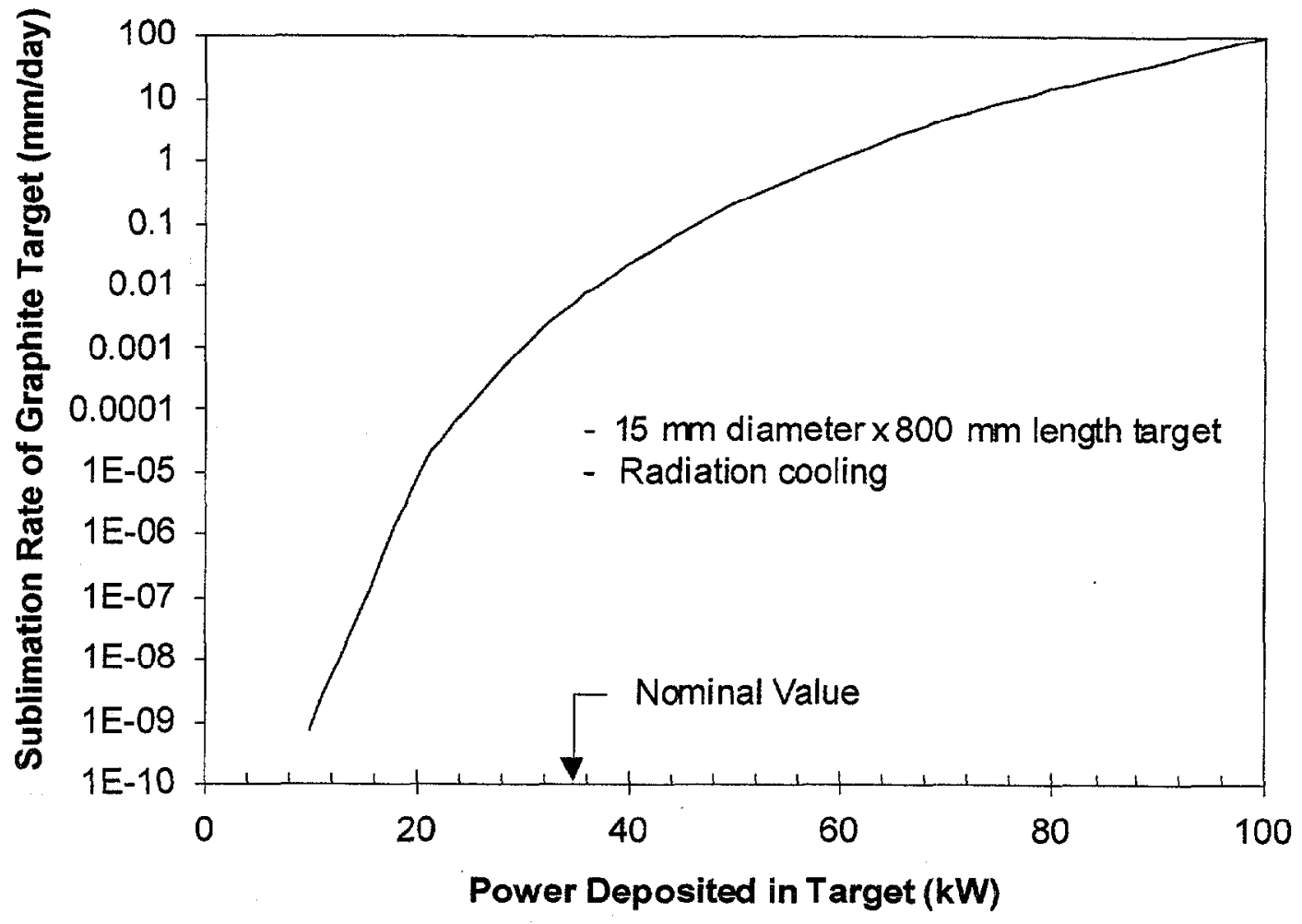

Fig. 11. Surface sublimation rate for a graphite target as a function of power deposition.

Other issues that are recommended for consideration in future studies include:

- Since radiation damage of graphite may be the life-limiting mechanism for the target, the irradiation database should be examined using existing data and if needed, additional irradiation tests should be performed,

- Carbon-carbon composites, which incorporate carbon fibers within a graphite matrix, to achieve improved thermal-mechanical properties and perhaps increased resistance to irradiation damage, and

- Develop design details for supporting the target within a water-cooled tube with spoke-like graphite supports that allow the target to freely expand as it heats up. 


\section{SHIELD ANALYSIS}

Neutron, gamma, and proton flux profiles in the target area and the low-field muon beam areas were generated to allow estimations of dose levels and activation and to evaluate shield dimensions.

\subsection{THE MODEL}

A Monte Carlo neutron, photon, charged particle transport code (MCNPX) using cylindrical geometry was prepared for neutronic calculations. The model describes the graphite target with a length of $80 \mathrm{~cm}$ and a diameter of $1.5 \mathrm{~cm}$ and tilted 50 mradians about the cylinder axis and centered in a high-field $(20 \mathrm{~T})$ magnet, which consists of a Bitter coil structure on the inside and a superconducting magnet on the outside-all being $120 \mathrm{~cm}$ in length. The radial build is shown in Table 2.

Table 3 lists the material composition for the superconducting winding.

Table 2. Radial build used for the neutronics model

\begin{tabular}{|l|l|}
\hline 0 to $7.5 \mathrm{~cm}$ & Vacuum zone for graphite target and beam transport \\
\hline 7.5 to $10 \mathrm{~cm}$ & Inner steel housing of Bitter magnet \\
\hline 10 to $30 \mathrm{~cm}$ & Bitter magnet (90\% copper, 10\% water) \\
\hline 30 to $33 \mathrm{~cm}$ & Outer steel housing of Bitter coil \\
\hline 33 to $45 \mathrm{~cm}$ & Tungsten shielding (75\% tungsten, $25 \%$ water) \\
\hline 45 to $50 \mathrm{~cm}$ & Superconducting cryostat and insulation (50\% steel, $25 \%$ vacuum) \\
\hline 50 to $75 \mathrm{~cm}$ & Superconducting winding (He, $\mathrm{C}, \mathrm{Fe}, \mathrm{Cu}, \mathrm{Nb})$ \\
\hline 75 to $80 \mathrm{~cm}$ & Superconducting cryostat and insulation ( $(50 \%$ steel, $25 \%$ vacuum) \\
\hline
\end{tabular}

Table 3. Material composition for the superconducting winding

\begin{tabular}{|c|c|}
\hline Element & Number density $\left(\mathrm{cm}^{-3}\right)$ \\
\hline $\mathrm{He}$ & 0.00372 \\
\hline $\mathrm{C}$ & 0.01565 \\
\hline $\mathrm{Fe}$ & 0.02714 \\
\hline $\mathrm{Cu}$ & 0.02078 \\
\hline $\mathrm{Nb}$ & 0.00245 \\
\hline
\end{tabular}

A pencil-thin beam of protons with a beam power of $1.5 \mathrm{MW}$ and a proton energy of $16 \mathrm{GeV}$ strikes the front side of the graphite target. Downstream of the PB the low-field muon beam tunnel is modeled as connecting directly to the high-field magnets. The tunnel structure is built of concentric ring zones with radial dimensions, as shown in Table 4.

The whole structure is enclosed in an iron shield extending radially to $120 \mathrm{~cm}$. 
Table 4. Radial build of the decay channel components

\begin{tabular}{|l|l|}
\hline 0 to $30 \mathrm{~cm}$ & Vacuum \\
\hline 30 to $55 \mathrm{~cm}$ & Tungsten shielding \\
\hline 55 to $60 \mathrm{~cm}$ & Superconducting cryostat and insulation $(50 \%$ steel, 25\% vacuum) \\
\hline 60 to $62.5 \mathrm{~cm}$ & Superconducting windings $(\mathrm{He}, \mathrm{C}, \mathrm{Fe}, \mathrm{Cu}, \mathrm{Nb})$ \\
\hline 62.5 to $67.5 \mathrm{~cm}$ & Superconducting cryostat and insulation $(50 \%$ steel, $25 \%$ vacuum $)$ \\
\hline
\end{tabular}

\subsection{RESULTS}

Six calculations were performed, with each calculation scoring the neutron and gamma leakage from the tungsten shield of the low-field tunnel at different sections along a 200-cm length. This information was used to calculate the required iron shield thickness of the tunnel, as discussed in the Section 3.3.

Furthermore, the neutron, gamma, and proton fluxes were tallied in the vacuum zones of the high-field magnet and the low-field tunnel. The flux averages of the six calculations were generated to minimize the statistical error of the Monte Carlo calculations. In order to obtain flux profiles along the tunnel axis, the tunnel was segmented into 1 -m-long sections.

The neutron, gamma, and proton flux spectra are presented in Figs. 9-11. The flux spectra drops off about a factor of 10-20 from the entrance to the exit of the low-field tunnel with few spectral changes in the neutron and gamma spectra. This means that at the end of the low-field tunnel there is still a significant radiation field. Assuming the same drop-off rate, the flux level in the muon decay tunnel (that extends $50 \mathrm{~m}$ beyond the low-field tunnel) would drop a factor of 1,000-8,000 from the entrance of the decay tunnel to the exit. This estimate is considered to be very conservative because no additional (significant) sources of neutrons are present that are part of the primary PB in the low-field tunnel.

\subsection{SHIELD DESIGN}

Table 5 is a listing of the dose levels calculated using the flux data shown previously. These are the operational dose levels assuming a $1.5-\mathrm{MW}$ beam power. Dose levels due to neutrons having energies above and below $1.0 \mathrm{GeV}$ are given. The reason for the breakdown is that only flux-to-dose conversion factors for neutron energies below $1.0 \mathrm{GeV}$ are available. For neutron energies above $1.0 \mathrm{GeV}$, the fluxes were scaled by the ratio of their energies to $975.0 \mathrm{MeV}$, that is, the midpoint energy of the highest energy group ( 950.0 to $1,000 \mathrm{MeV}$ ) flux to dose conversion factor. After scaling, the highest energy group flux-to-dose conversion factor was then used.

All of the dose levels in Table 5 are given in $\mathrm{mrem} / \mathrm{h}$. In general, the dose due to activation is between 1,000 and 10,000 times lower than the operating dose due to neutrons. Assuming this to be the case here, at shutdown, the dose level out to $15 \mathrm{~m}$ were between about 300 and $3,000 \mathrm{rem} / \mathrm{h}$ - which would preclude hands on maintenance. 
Table 5. Dose levels in the target region and the decay channel region, in $\mathrm{mrem} / \mathrm{h}$ at $1.5-\mathrm{MW}$ beam power

\begin{tabular}{|r|c|c|c|}
\hline Dose levels in target area & Dose $>1 \mathrm{GeV}^{\mathrm{a}}$ & Dose $<1 \mathrm{GeV}$ & Total dose \\
\hline & $7.4515 \mathrm{E}+11$ & $9.7505 \mathrm{E}+11$ & $1.7202 \mathrm{E}+12$ \\
\hline $\begin{array}{c}\text { Tunnel segment locations } \\
\text { (downstream from target m) }\end{array}$ & (mrem/h) & (mrem/h) & (mrem/h) \\
\hline 0.2 to 0.70 & $1.0005 \mathrm{E}+11$ & $1.7095 \mathrm{E}+11$ & $2.7099 \mathrm{E}+11$ \\
\hline 0.7 to 1.70 & $9.6226 \mathrm{E}+10$ & $1.3606 \mathrm{E}+11$ & $2.3228 \mathrm{E}+11$ \\
\hline 1.7 to 2.70 & $8.3777 \mathrm{E}+10$ & $1.9958 \mathrm{E}+11$ & $2.8335 \mathrm{E}+11$ \\
\hline 2.7 to 3.70 & $6.2515 \mathrm{E}+10$ & $2.4726 \mathrm{E}+11$ & $3.0977 \mathrm{E}+11$ \\
\hline 3.7 to 4.70 & $4.4562 \mathrm{E}+10$ & $2.2039 \mathrm{E}+11$ & $2.6495 \mathrm{E}+11$ \\
\hline 4.7 to 5.70 & $3.3549 \mathrm{E}+10$ & $3.1250 \mathrm{E}+11$ & $3.4605 \mathrm{E}+11$ \\
\hline 5.7 to 6.70 & $2.8647 \mathrm{E}+10$ & $3.6626 \mathrm{E}+11$ & $3.9491 \mathrm{E}+11$ \\
\hline 6.7 to 7.70 & $2.3574 \mathrm{E}+10$ & $1.3264 \mathrm{E}+11$ & $1.5621 \mathrm{E}+11$ \\
\hline 7.7 to 8.70 & $1.9190 \mathrm{E}+10$ & $7.6736 \mathrm{E}+10$ & $9.5926 \mathrm{E}+10$ \\
\hline 8.7 to 9.70 & $1.5758 \mathrm{E}+10$ & $5.3156 \mathrm{E}+10$ & $6.8914 \mathrm{E}+10$ \\
\hline 9.7 to 10.70 & $1.3255 \mathrm{E}+10$ & $3.8942 \mathrm{E}+10$ & $5.2196 \mathrm{E}+10$ \\
\hline 10.7 to 11.70 & $1.1229 \mathrm{E}+10$ & $2.9572 \mathrm{E}+10$ & $4.0801 \mathrm{E}+10$ \\
\hline 11.7 to 12.70 & $9.7006 \mathrm{E}+09$ & $2.2883 \mathrm{E}+10$ & $3.2584 \mathrm{E}+10$ \\
\hline 12.7 to 13.70 & $8.4020 \mathrm{E}+09$ & $1.8354 \mathrm{E}+10$ & $2.6756 \mathrm{E}+10$ \\
\hline 13.7 to 16.00 & $1.1923 \mathrm{E}+10$ & $2.2099 \mathrm{E}+10$ & $3.4022 \mathrm{E}+10$ \\
\hline
\end{tabular}

${ }^{2}$ Dose $>1 \mathrm{GeV}$ due to neutrons with energies greater than $1 \mathrm{GeV}$.

${ }^{b}$ Dose $<1 \mathrm{GeV}$ due to neutrons with energies less than $1 \mathrm{GeV}$.

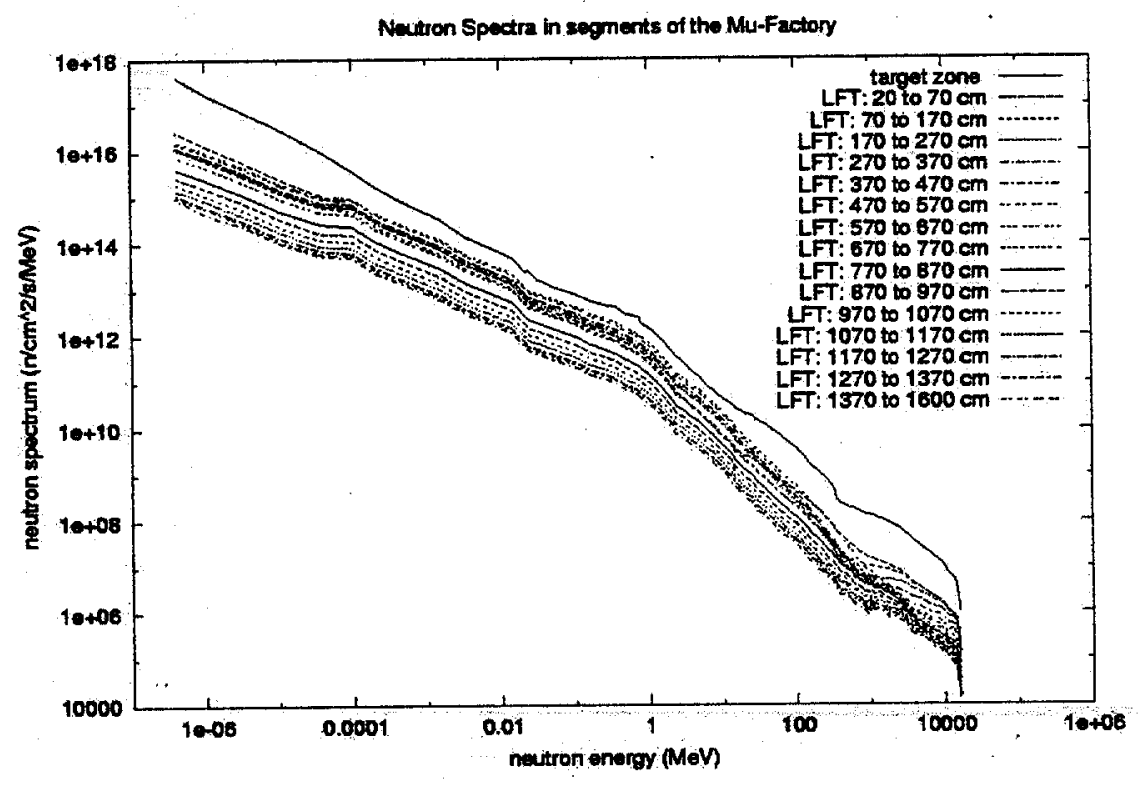

Fig. 12. Neutron spectra in vacuum zones of the high-field magnet and the low-field tunnel. 


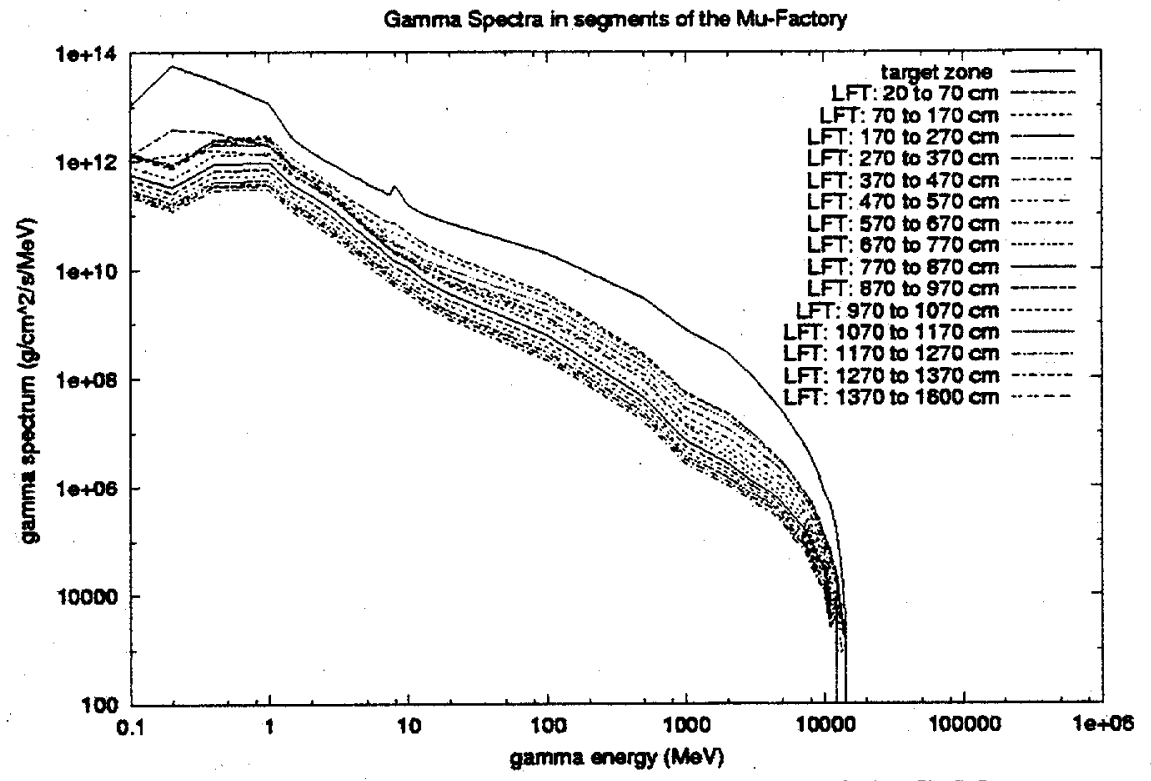

Fig. 13. Gamma spectra in vacuum zones of the high-field magnet and the low-field tunnel.

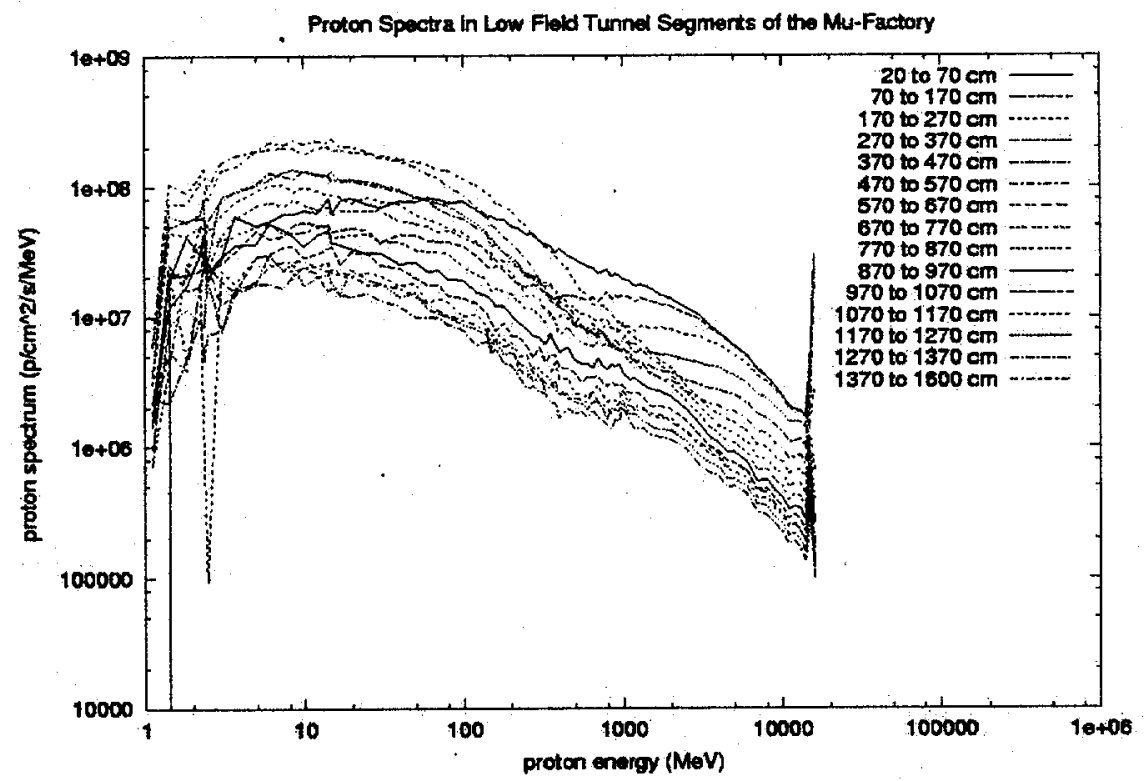

Fig. 14. Proton spectra in vacuum zones of the high-field magnet and the low-field tunnel.

In addition, one-dimensional cylindrical radiation transport calculations were made to estimate the shielding required downstream from the target using the source provided above. The results are summarized in Table 6 . In order to minimize the total shield thickness, inner steel thicknesses of $13.1 \mathrm{ft}(4.0 \mathrm{~m})$ and $14.8 \mathrm{ft}(4.5 \mathrm{~m})$ are required to obtain a contact dose of $0.25 \mathrm{mrem} / \mathrm{h}$ at the outer surface of the shield. On the other hand, to minimize the steel thickness while maintaining a constant total shield thickness of 
$16.2 \mathrm{ft}(4.9 \mathrm{~m})$, inner steel thicknesses of between $11.5 \mathrm{ft}(3.5 \mathrm{~m})$ and $14.8 \mathrm{ft}(4.5 \mathrm{~m})$ are required. Although these results are approximate, they provide a rough estimate of the steel and concrete needed to obtain $0.25 \mathrm{mrem} / \mathrm{h}$.

Table 6. Shield thickness estimate in the first $15 \mathrm{~m}$ of the decay channel

\begin{tabular}{|l|c|c|c|c|c|c|}
\hline \multicolumn{7}{|c|}{ Distance downstream from target (m) } \\
\hline & 3 to 5 & 5 to 7 & 7 to 9 & 9 to 11 & 11 to 13 & 13 to 15 \\
\hline Shield Thickness Criteria & & & & & & \\
\hline \multicolumn{7}{|c|}{ Steel thickness (ft)/concrete thickness (ft) } \\
\hline Minimum total thickness & $14.8 / 1.0$ & $14.8 / 1.4$ & $14.2 / 0.9$ & $13.9 / 1.0$ & $13.1 / 1.6$ & $14.1 / 1.0$ \\
\hline Minimum steel thickness & $14.2 / 2.0$ & $14.8 / 1.4$ & $12.8 / 3.4$ & $11.8 / 4.4$ & $11.5 / 4.7$ & $12.1 / 4.1$ \\
\hline
\end{tabular}

\subsection{BEAM ABSORBER FLUX CONTRIBUTION}

It was suspected that the high neutron flux in the downstream region of the decay channel might be caused by the PB striking the beam absorber in the vicinity of $Z=6 \mathrm{~m}$. Eliminating the remainder of the primary $\mathrm{PB}$, which hits the tungsten shield in the low-field tunnel at about $6 \mathrm{~m}$ (the protons that hit a 2-m-long section of tungsten around the location $6 \mathrm{~m}$ were terminated), reduces the neutron and gamma radiation downstream in the tunnel, but not by very much, as shown in Table 7 .

The table lists total fluxes in all the target areas and the segments of the low-field tunnel. The columns listing "All protons" give the results of the previous calculation, which are shown in. Figs. 9 and 10, respectively; the columns listing "Terminated protons" give the results of the latest case with terminated protons. The neutron and gamma spectra are very similar to those of the previous calculation.

Table 7. Total neutron and gamma fluxes without the beam absorber contribution downstream to $Z=16 \mathrm{~m}$

\begin{tabular}{|c|c|c|c|c|}
\hline & \multicolumn{2}{|c|}{ Total Neuton Flux } & \multicolumn{2}{c|}{ Total Gamma Flux } \\
\hline Segment & All protons & Terminated protons & All protons & Terminated protons \\
\hline (cm to $\mathrm{cm})$ & (n/cm**2/s) & $\left(\mathrm{n} / \mathrm{cm}^{* *} 2 / \mathrm{s}\right)$ & $\left(\mathrm{g} / \mathrm{cm}^{* *} 2 / \mathrm{s}\right)$ & $\left(\mathrm{g} / \mathrm{cm}^{* *} 2 / \mathrm{s}\right)$ \\
\hline target & $9.6911 \mathrm{e}+12$ & $9.6495 \mathrm{e}+12$ & $2.9729 \mathrm{e}+13$ & $2.9731 \mathrm{e}+13$ \\
\hline 20 to 70 & $1.8919 \mathrm{e}+12$ & $1.8818 \mathrm{e}+12$ & $4.7647 \mathrm{e}+12$ & $4.7907 \mathrm{e}+12$ \\
\hline 70 to 170 & $1.5281 \mathrm{e}+12$ & $1.5206 \mathrm{e}+12$ & $3.1056 \mathrm{e}+12$ & $3.1449 \mathrm{e}+12$ \\
\hline 170 to 270 & $2.0809 \mathrm{e}+12$ & $2.0988 \mathrm{e}+12$ & $3.3005 \mathrm{e}+12$ & $3.3192 \mathrm{e}+12$ \\
\hline 270 to 370 & $2.5212 \mathrm{e}+12$ & $2.4968 \mathrm{e}+12$ & $3.7693 \mathrm{e}+12$ & $3.7820 \mathrm{e}+12$ \\
\hline 370 to 470 & $2.2949 \mathrm{e}+12$ & $2.0483 \mathrm{e}+12$ & $3.4240 \mathrm{e}+12$ & $3.3310 \mathrm{e}+12$ \\
\hline 470 to 570 & $3.1645 \mathrm{e}+12$ & $1.1266 \mathrm{e}+12$ & $3.7925 \mathrm{e}+12$ & $2.4159 \mathrm{e}+12$ \\
\hline 570 to 670 & $3.6004 \mathrm{e}+12$ & $5.4587 \mathrm{e}+11$ & $4.5052 \mathrm{e}+12$ & $1.5945 \mathrm{e}+12$ \\
\hline 670 to 770 & $1.4011 \mathrm{e}+12$ & $4.7507 \mathrm{e}+11$ & $2.3729 \mathrm{e}+12$ & $1.2952 \mathrm{e}+12$ \\
\hline 770 to 870 & $7.9235 \mathrm{e}+11$ & $4.7067 \mathrm{e}+11$ & $1.5967 \mathrm{e}+12$ & $1.1328 \mathrm{e}+12$ \\
\hline 870 to 970 & $5.3975 \mathrm{e}+11$ & $3.8577 \mathrm{e}+11$ & $1.1962 \mathrm{e}+12$ & $9.2990 \mathrm{e}+11$ \\
\hline 970 to 1070 & $3.9134 \mathrm{e}+11$ & $2.9575 \mathrm{e}+11$ & $9.3197 \mathrm{e}+11$ & $7.5742 \mathrm{e}+11$ \\
\hline 1070 to 1170 & $2.9506 \mathrm{e}+11$ & $2.3312 \mathrm{e}+11$ & $7.4797 \mathrm{e}+11$ & $6.3161 \mathrm{e}+11$ \\
\hline 1170 to 1270 & $2.2796 \mathrm{e}+11$ & $1.8900 \mathrm{e}+11$ & $6.1290 \mathrm{e}+11$ & $5.3764 \mathrm{e}+11$ \\
\hline 1270 to 1370 & $1.8210 \mathrm{e}+11$ & $1.5578 \mathrm{e}+11$ & $5.1870 \mathrm{e}+11$ & $4.4537 \mathrm{e}+11$ \\
\hline 1370 to 1600 & $1.2125 \mathrm{e}+11$ & $1.0064 \mathrm{e}+11$ & $3.8147 \mathrm{e}+11$ & $3.3290 \mathrm{e}+11$ \\
\hline
\end{tabular}





\section{CRANE HALL AND REMOTE HANDLING}

The crane hall is located over the entire target support facility. It is $12 \mathrm{~m}$ above the floor level and $80 \mathrm{~m}$ long and contains a 40-ton overhead crane and a bridge-mounted manipulator system. The floor of the hall consists of removable shield slabs, which provide access into the target region and the decay channel. Figure 2 shows the extent of the crane hall over the proton tunnel, the target region, and the decay channel.

\subsection{HOT CELL}

The hot cell contains a 20-ton bridge crane, overhead manipulator, through-the-wall manipulator, shield window, closed-circuit television (CCTV) viewing, and lighting. There are provisions to add up to three additional wall manipulators and windows. The hot-cell size is determined by the floor space needed for the routine replacements, as shown in Table 1, plus the handling of a 4-m-long cryostat for the possible replacement of a solenoid coil. The operations in the cell are primarily handling the radioactive waste created by periodic replacement of the target, Bitter magnet, and PB window. These life-limited components are not repairable because of the nature of their radiation damage and are temporarily stored in the hot cell before their disposal. They are brought into the hot cell with the 40 -ton crane by removing one or more of the three roof plugs. The hot-cell floor contains shielded storage areas for up to four targets, two Bitter coils, and one PB window. The hot cell is partially located over the PB tunnel and has floor plugs, which provide access to the PB focusing magnets and instrument module. Remote replacement of the instrumentation on this module is done in the hot cell annually. Figure 15 is a side elevation of the hot-cell area, and Fig. 16 shows a cross-section through the hot cell.

\subsection{REMOTE-HANDLING EQUIPMENT}

Remote-handling operations are required on all of the components located in the target region and the decay channel. However, when the crane hall floor shielding is in place, unlimited personnel access is permitted in the crane hall even with the beam on. This is the most cost-effective way to design the shield since meeting site-boundary radiation criteria are efficiently met by placing shield material as close to the source of radiation as possible. The requirements for lifting and remotely handling the components are determined by their weight and size. For example, the crane-lifting capacity was determined by the high-field cryostat module, which is the heaviest component that could require handling during the facility lifetime. Table 8 is a listing of the size and weight of the key components.

The bridge-mounted manipulators, which are located in the crane hall and hot cell, are commercially available, single-arm, force-reflecting systems. The manipulators are used in conjunction with special fixtures for lifting and handling (e.g., the target module, Bitter coil, PB window). These manipulators are operated from control stations located 
in the hot cell gallery, and their operations require remote viewing. The through-the-wall manipulators in the hot cell are used in conjunction with a shielded viewing window for operations that can be done at a work station.

Table 8. Component weights and sizes

\begin{tabular}{|c|c|c|}
\hline Component & Weight (lb) & Size $(\mathrm{m})$ \\
\hline HF cryostat & 72,500 & 1.5 diam $\times 4.2$ \\
\hline HF S/C Coil & 18,000 & 1.5 diam $\times 1.2$ \\
\hline Tungsten shield module & 44,000 & 1.0 diam $\times 4.0$ \\
\hline LF cryostat/steel shield & 44,000 & 1.3 diam $\times 4.0$ \\
\hline Steel shield slabs & 72,000 & $0.4 \times 1.0 \times 3.0$ \\
\hline Verticle-steel shield blocks & 28,000 & $0.6 \times 1.2 \times 2.0$ \\
\hline
\end{tabular}

\subsection{REMOTE-HANDLING OPERATIONS}

The maintenance philosophy for dealing with the life-limited components is to replace them at scheduled intervals with new modular components. Since they are not repairable, they will be handled as radioactive waste. Therefore, the need for special-purpose tools and handling fixtures is minimal. Furthermore, almost all of the components that require periodic replacement are located in the target region; hence, many of the remote-handling tasks are common to each other. As a result, a preliminary estimate of downtime to replace life-limited components (Table 1) was found to be within a reasonable allocation of time for scheduled maintenance activities.

The typical tasks for replacing the target, Bitter coil, and PB window are as follows:

- remove the stacked shielding above the helium vessel (crane and personnel)

- remove the 2-m port cover (crane and personnel)

- decouple water connectors for each steel shield block and remove the blocks that surround the target (this task and the remainder are remote)

- decouple instrument and water line connectors to the target, unbolt the target module, disengage and remove with the bridge manipulator

- decouple instrument connectors and water lines to the Bitter magnet, unbolt the coil flange from the tungsten shield flange, engage a crane-mounted handling fixture for removal

- decouple instrument connectors and water lines to the PB window, disengage the commercial remote-connector with manipulator tools, remove with the bridge manipulator and holding fixture

- replacement of these components follows the reverse order. 


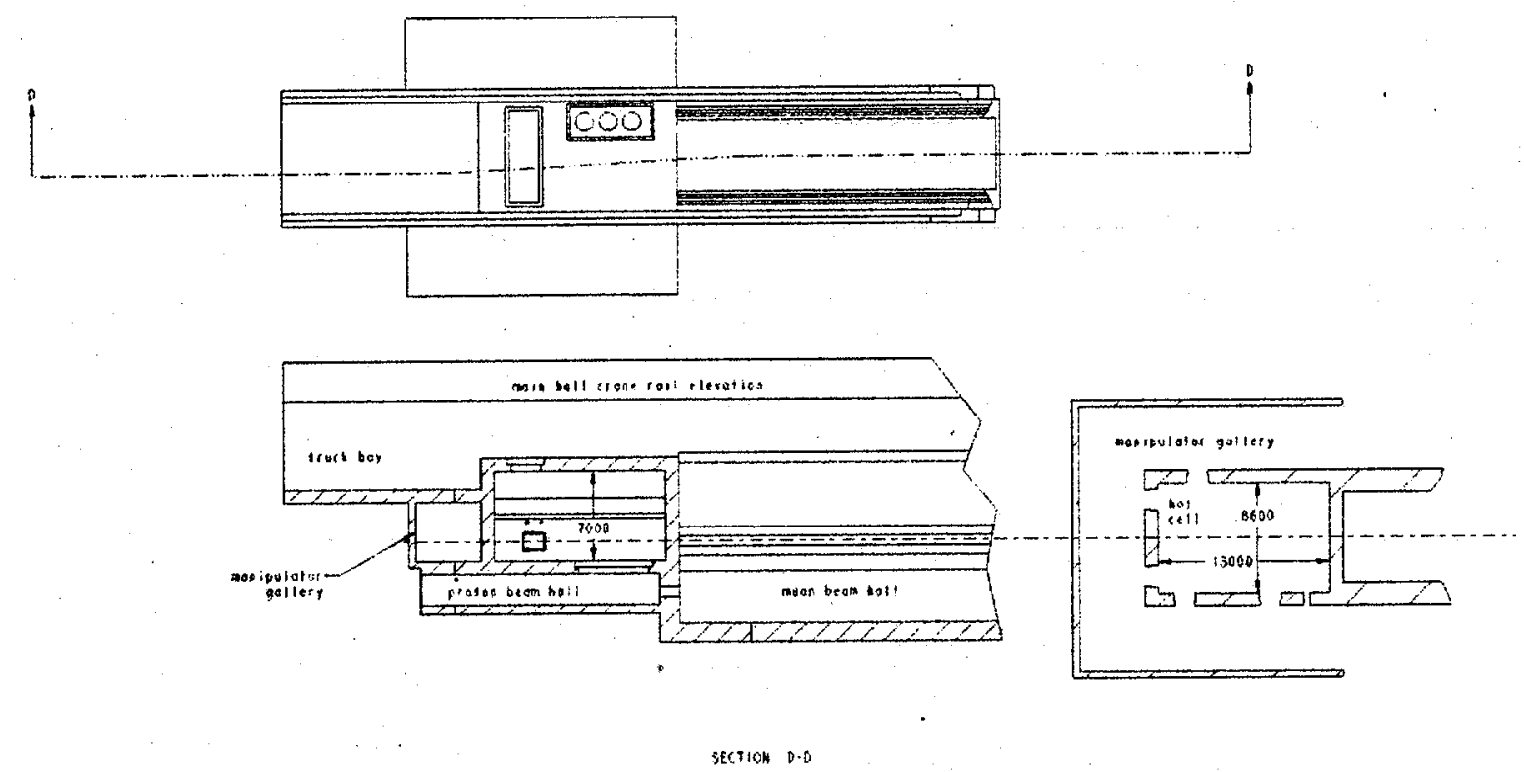

Fig. 15. Side elevation of the hot-cell area. 


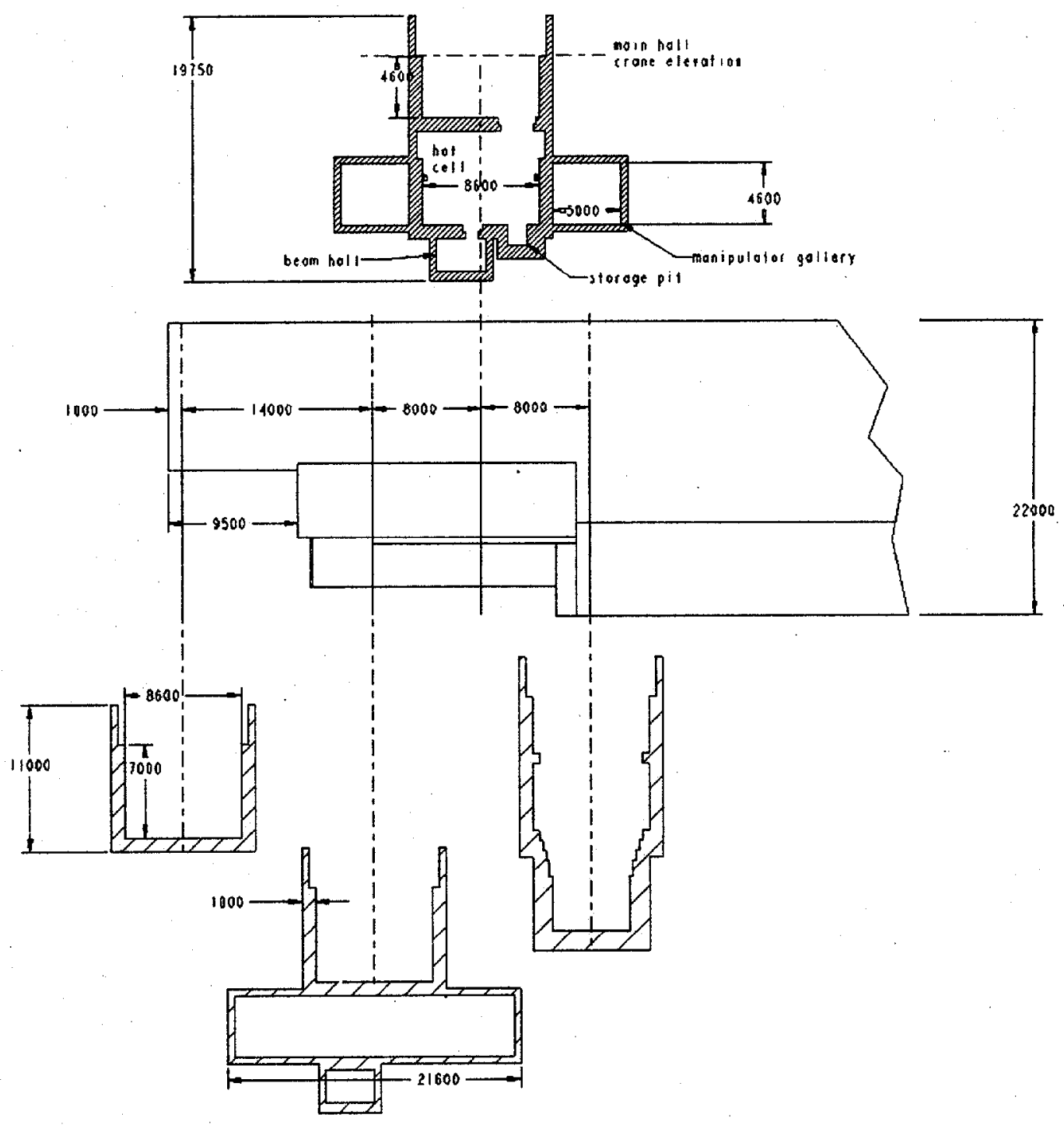

Fig. 16. Section cut through the hot cell. 


\section{COST ESTIMATE}

The cost estimate for the Target Support Facility is in fiscal year (FY) 2000 dollars and includes the cost of materials, of vendor-supplied components, and of the assembly and installation of components. Engineering, quality assurance (QA), and procurement services are listed separately. These were estimated on the basis of a four-year engineering program consisting of conceptual design, preliminary design, final design, and procurement and installation support. Also included is the cost of spare components that are required for the first year of operation, such as target modules, which are replaced every three months. The cost estimate does not include any burdens or contingency, nor any of the associated research and development (R\&D) for the Target Support Facility. The estimate is divided into construction costs and equipment costs. Table 9 is a summary of the major cost categories. Note that the "subtotal" amounts do not exactly add up from the constituent costs due to escalation adjustments.

The construction costs include the labor and materials for excavation, form work, reinforcement, concrete for walls and slabs, roof slabs, concrete finishing, and the steel and concrete shield slabs that cover the decay channel. The equipment costs include the tungsten and steel shielding (that protect the magnets), steel shield blocks in the tunnel area for ground water protection, cranes, manipulators, and other remote-handling equipment. Installation costs for the equipment are also included.

Table 9. Summary of the Target Support Facility costs

\begin{tabular}{|c|c|}
\hline Construction costs & SK \\
\hline Crane bay/target region/decay channel & 23,596 \\
\hline Hot cell & 1,418 \\
\hline Truck bay & 470 \\
\hline Engineering/QA/procurement & $\underline{5.200}$ \\
\hline Subtotal & 31,194 \\
\hline \multicolumn{2}{|l|}{ Equipment costs } \\
\hline Target area & 1,151 \\
\hline Crane hall & 663 \\
\hline Decay channel & 5,559 \\
\hline Hot cell & 1,259 \\
\hline Engineering/QA/procurement & $\underline{4.800}$ \\
\hline Subtotal & 13,616 \\
\hline Target Support Facility total cost & 44,810 \\
\hline
\end{tabular}




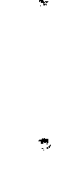




\section{DESIGN ISSUES}

A number of design issues for the Target Support Facility require additional work to determine their respective impacts on meeting the overall facility requirements and their impacts on cost. Below is a listing of issues that fall into the categories of $R \& D$ and design.

- Develop a detailed design of the graphite target, its support structure, and cooling scheme based on results of R\&D testing for thermal shock, creep effects, and cooling.

- Develop a design for the beam dump located at $5.5<Z<6.5$ meters, including the coolant connections and piping arrangement:

- determine the impact the beam dump design has on the low-field solenoid, which is located in the same region, in terms of diameter and nuclear shield requirement.

- Develop details of the utility connections in the target region and assess the impact on remote-handling operations:

- water-cooling connections and piping for the target support tube

- instrumentation leads for the target and the Bitter coil

- water-cooling connections, piping, and power leads for the Bitter coil

- water-cooling connections and piping for the nuclear shielding

- power leads, cryogenic connections and piping for the superconducting coils.

- Develop details of the utility connections in the decay channel and assess their impact on remote handling operations:

- water cooling, power leads, and cryogenic connections and piping to the low field solenoids.

- Expand the neutronic analysis to assess air activation fall-off.

- Develop details for the helium environment; purge air; helium-air containment and processing. 



\section{CONCLUSIONS}

The conceptual design of a target support facility was developed for a neutrinoproducing research facility. The design is based on using a radiatively-cooled graphite target, which interacts with a $16-\mathrm{GeV}, 4-\mathrm{MW}$ proton beam. The target is located in a high-field ( $20 \mathrm{~T})$ solenoid magnet region consisting of a (resistive) Bitter coil and a $\mathrm{Nb}_{3} \mathrm{Sn}$ superconducting coil. Muons are collected in a decay channel, which consists of low-field $(1.25 \mathrm{~T})$ solenoid $\mathrm{NbTi}$ superconducting magnets. Because of high neutron fluxes produced in the target region, use of remotely operated equipment is required to maintain the target system, including the decay channel.

A preliminary cost estimate was prepared in support of the design effort. The level of preconceptual design work presented in this report demonstrates the feasibility of developing this concept in a cost-effective manner. Additional design details should be developed for the graphite target and its support structure, based on results of R\&D testing that address thermal shock, sublimation, and cooling. In addition, further design details should be developed for the various utility connections that the target and magnets require to fully quantify remote-handling issues. 



\section{REFERENCES}

1. "Target Systems," Chatper 6 in Spallation Neutron Source Design Manual, Oak Ridge National Laboratory, October 1998.

2. N. V. Mokhov, " $\pi / \mu$ Yield and Power Dissipation for Carbon and Mercury Targets in 20-Tesla Solenoid with Matching Section," Mucool Note MUCOO61, Fermi National Laboratory, Batavia, Illinois (1999), http://www-ap-fnal.gov/mokhov/mumu/target99/mu00061 and updates at http://www-ap-fnal.gov/mokhov/mumu/target00.

3. N. Holtkamp et al., "FNAL Feasibility Study on a Neutrino Source Based on a Muon Storage Ring," Fermi National Laboratory, Batavia, Illinois, April 2000, htttp://fnal.gov/projects/muon_collider/nu-factory/. 


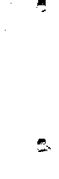

$=$ 
ORNL/TM-2000/153

\section{INTERNAL DISTRIBUTION}

1. F. E. Bertrand

2. J. B. Chesser

3. T. A. Gabriel

4. F. X. Gallmeier

5. R. G. Gilliland

6. J. R. Haines

7. D. C. Haley

8. J. N. Herndon

9. R. A. Lillie

10. T. E. Mason
11. T. J. McManamy

12. G. E. Michaels

13. F. G. Pin

14. S. L. Schrock

15-19. P. T. Spampinato

20. C. N. Strawbridge

21. L. E. Temple

22. ORNL Central Research Library

23. Laboratory Records

\section{EXTERNAL DISTRIBUTION}

24. Sam Childress, Fermilab, P.O. Box 500, BD-NUMI, Mail Station 220, WH 12W, Batavia, IL 60510-0500

25. David Finley, Fermilab, P.O. Box 500, TD-Administration, Mail Station 316, ICB 2 W, Batavia, IL 60510-0500

26. Thomas Handler, University of Tennessee, Physics Departmetn, 404 Neilsen Physics Building, Knoxville, TN 37996

27. Norbert Holtkamp, Fermilab, P.O. Box 500, BD-Muon Colliders, Mail Station 221, WH 13E, Batavia, IL 60510-0500

28. Harold Kirk, Brookhavan National Laboratory, P.O. Box 5000, Physics Department, Building 901A, Upton, NY 11973-5000

29. Kirk McDonald, Princeton University, Physics Department, 309 Jadwin Hall, Princeton, New Jersey 08544

30. Nikolai Mokhov, Fermilab, P.O. Box 500, BD-DH-Beam Physics Department, Mail Station 220, WH 12E, Batavia, IL 60510-0500

31. John R. O’Fallon, Director, High Energy Physics Division, 19901 Germantown Road, SC-22, Room G-454, Germantown, MD 20874

32. S. P. Rosen, Office of High Energy and Nuclear Physics, U.S. Department of Energy, 19901 Germantown Road, SC-20, Room H-410, Germantown, MD 20874

33. Andrew Sessler, Lawrence Berkeley National Laboratory, Accelerator and Fusion Research Division, 1 Cyclotron Road, Mailstop 71-259, Berkeley, CA 94720

34. Thomas E. Shannon, University of Tennessee, Mechanical and Aerospace Engineering and Engineering Science Department, 414 Dougherty Engineering Building, Knoxville, TN 37996

35. Alvin Tollestrup, Fermilab, P.O. Box 500, PPD-EPP Exp. Physics Projects, Mail Station 221, WH 13E, Batavia, IL 60510-0500 
36. P. K. Williams, High Energy Physics Division, 19901 Germantown, Road, SC-22, Room G-447, Germantown, MD 20874

37. Michael Witherell, Fermilab, P.O. Box 500, DO-Directorate, Mail Station 105, WE 2E, Batavia, IL 60510-0500

38. Bernhard Zeitnitz, Forschungszentrum Karlsruhe $\mathrm{GmbH}$, Institut für Kernphysik I, postfach 3640, D-76021 Karlsruhe, Germany

39. Christian Zeitnitz, Institut fuer Physik, Universitaet 55099 Mainz, Germany

40. Michael Zisman, Lawrence Berkeley National Laboratory, Accelerator and Fusion Research Division, 1 Cyclotron Road, Mailstop 71-259, Berkeley, CA 94720

41. Office of Scientific and Technical Information, P.O. Box 62, Oak Ridge, TN 37831 